\title{
How human thermal plume influences near-human transport of respiratory droplets and airborne particles: a review
}

\author{
Shiyi Sun ${ }^{1}$. Jing $\mathrm{Li}^{1} \cdot \mathrm{Jie} \mathrm{Han}^{1}$ (D)
}

Received: 18 December 2020 / Accepted: 28 December 2020 / Published online: 21 January 2021

(c) The Author(s), under exclusive licence to Springer Nature Switzerland AG part of Springer Nature 2021

\begin{abstract}
With mounting evidence and notable cases of large clustered infections, airborne transmission via droplets and particles has been recently acknowledged as an effective mode of transmission for COVID-19. How droplets and aerosol particles disperse are being transported into the human breathing zone- the last few inches for airborne transmission to effectuate-remains a key question which has been widely overlooked. Human thermal plume refers to the constantly rising airflows around the boundary layer of human body due to persisting temperature gradients between the body surfaces and the ambient air. Ample evidence indicated that the thermal plume controls the dispersion and transport of aerosols in the human microenvironment. Given that in calm indoor environments most air inhaled by human comes from the boundary layer where thermal plume flows through constantly, the role of thermal plume needs to be scrutinized to predict the diffusion of droplets, aerosols and other airborne carriers of the novel coronavirus around the human body for prioritizing infection control strategies. Here, we assessed the potential influences of the thermal plume on the transmission of COVID-19 and other airborne pathogens by reviewing the most pertinent evidence and analyzing key variables in the formation of thermal plume in indoor environments, e.g., ambient temperature, human posture and type of clothing. Our reviewed evidence and data indicate that the human thermal plume should facilitate the airborne transmission of COVID-19 in enclosed spaces by elevating small droplets and airborne particles into the breathing zone from lower regions and ascending respiratory droplets from the sources into the upper atmosphere. By drawing attention to aerosol transport dynamics in the human microenvironment, these insights may be useful for understanding COVID-19 transmission in enclosed spaces, especially those intended for public use.
\end{abstract}

Keywords Coronavirus $\cdot$ SARS-CoV-2 $\cdot$ Respiratory droplet $\cdot$ Droplet nuclei $\cdot$ Aerosol particle $\cdot$ Indoor air

\section{Introduction}

Since early in the pandemic, airborne transmission has generated much debate. On October 5, 2020, the US Centers for Disease Control and Prevention (CDC) updated their guidance and for the first time, acknowledged airborne transmission via small droplets and particles as an effective route of virus spread during the current pandemic (CDC 2020a). Developing a better understanding of near-human transport of virus-laden droplets and aerosol particles is the key to control human infections via this particular transmission route. In this domain, current studies and regulatory guidelines have largely focused on the macro aspects,

Jie Han

jiehan@xjtu.edu.cn

1 Department of Environmental Science and Engineering, Xi' an Jiaotong University, Xi' an 710049, China e.g., requirements on a social distance of at least six feet and restrictions on using air conditioning and circulation in buildings, to prevent the spread of the virus via airborne routes (US EPA 2020a, 2020b; WHO 2020a). Yet, how these droplets and particles disperse and being transported into the human microenvironment- the last few inches for airborne transmission to effectuate-is an urgent question that has not been brought up in recent studies, scholarly discussions or risk assessments (CDC 2020a; WHO 2020b, 2020c).

Along with this gap is the fact that most of our inhaled air comes from the human boundary layer in calm indoor environments (Clark and Cox 1973; Craven and Settles 2006; Melikov 2015; Zhu et al. 2005). As an essential part of the human microenvironment, thermal plume has dominant influences on airflows in the boundary layer and around the human body, affecting the diffusion, transport and inhalation of atmospheric particulates and pollutants therein (Ansaripour et al. 2016; Craven and Settles 2006; Melikov 2015; 
Vianello et al. 2019; Yang et al. 2015). While there has been no systematic study on human thermal plume in the COVID19 context, an existing body of evidence suggests that it generates constant uprising airflows around the human body and transports aerosols from lower regions into the breathing zone. In the meantime, HTP intercepts respiratory droplets from the source and ascends them along the human boundary layer into the upper atmosphere (Vianello et al. 2019; Yan et al. 2019). Given the fact that air inhaled by indoor occupants often comes from the boundary layer where the thermal plume flows through constantly, it is imperative to scrutinize its role in effectuating the transmission of COVID-19 in the human microenvironment.

In this article, we discuss the underlying influences of human thermal plume on the transmission of airborne pathogens by gathering the most pertinent evidence and analyzing the key characteristics and influencing factors of thermal plume formed in indoor environments. By focusing on thermal plume-induced airflows and resultant aerosol transport in and out from the human microenvironment (Fig. 1), we highlight this issue as an important knowledge gap in current understanding of airborne transmission of COVID-19. Specifically, our discussions revolve the following topics: (1) the evolving understanding on the airborne transmission of COVID-19 and the impact of airborne particles, (2) the formation and characteristics of thermal plume and key influencing factors, (3) the influences of thermal plume on the diffusion and transport of indoor aerosols as potential virus carriers in the human microenvironment and (4) practical strategies for indoor occupants, especially those with a sedentary lifestyle, to mitigate the risk of inhaling virus-laden droplets and particles rising from the floors or lower regions in indoor environments.

\section{Transmission of COVID-19 by virus-laden droplets and indoor aerosols}

Severe acute respiratory syndrome coronavirus 2 (SARSCoV-2), the causation agent of the current COVID-19 pandemic, is primarily transmitted via respiratory droplets, contact surfaces (Han et al. 2020; Wang et al. 2020a) and fecal routes (Sun and Han 2020a), the former being generated by human respiratory activities such as coughing, sneezing and talking (WHO 2020b). Recently, researchers began to realize that airborne transmission played an essential role in several large clustered infections of COVID-19 (Lewis 2020). Meanwhile, studies have shown that SARS-CoV-2 virus-laden aerosol particles remained infectious for hours under the room temperature (van Doremalen et al. 2020; Fears et al. 2020). On July 6, 2020, Morawska et al. (2020) published an open commentary with signatories of 237 researchers, calling for immediate regulatory actions to mitigate the risks of airborne transmission of SARS-CoV-2. The World Health Organization (WHO) subsequently published a scientific brief to raise public awareness and to highlight current knowledge gaps on this issue (WHO 2020a). Three months later, the US Centers for Disease Control and Prevention (CDC) acknowledged the importance of airborne transmission in the current spread of the novel coronavirus (CDC 2020a). The risks of SARS-CoV-2 transmission via aerosols have been evaluated in high-risk settings, including correctional and detention facilities (CDC 2020b), public

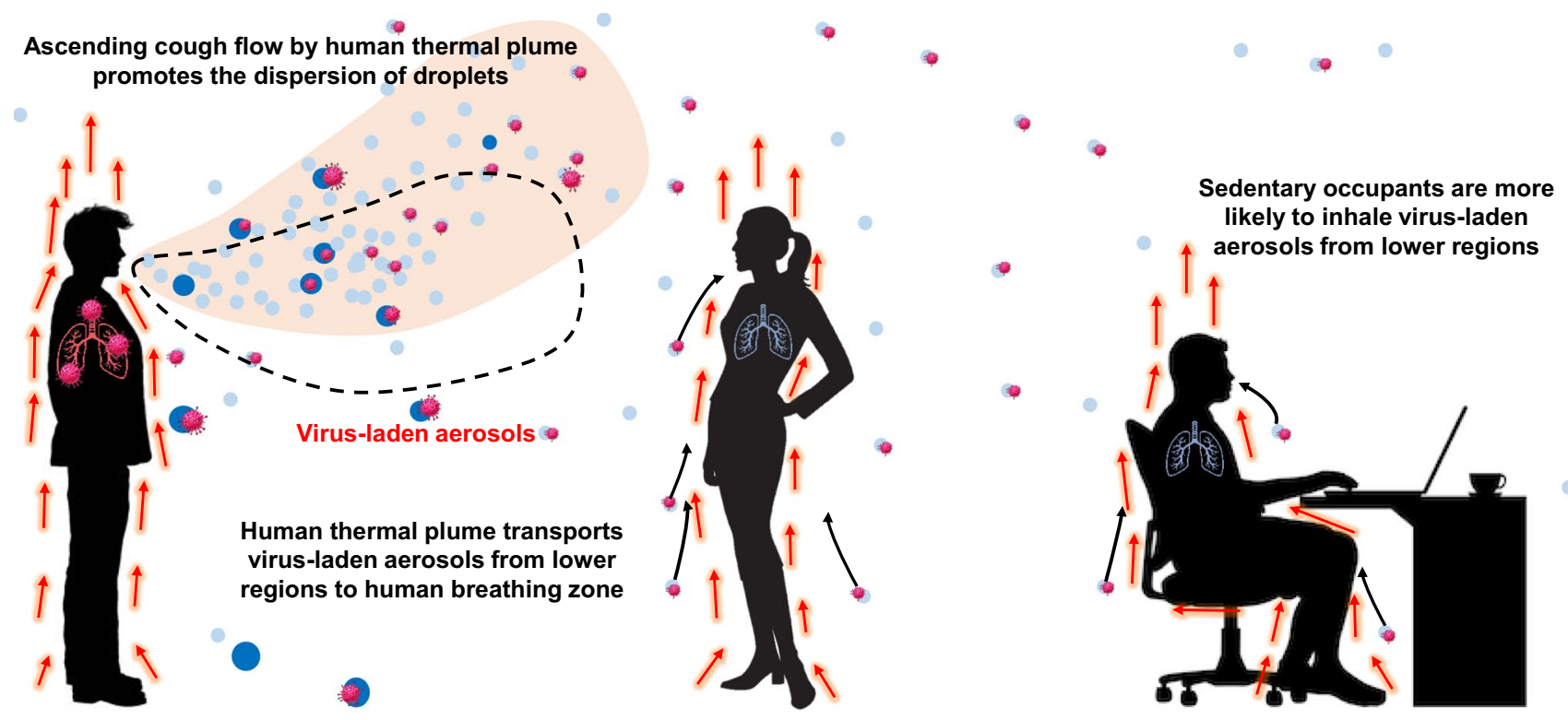

Fig. 1 Potential influences of human thermal plumes on airborne transmission of COVID-19 
toilets (Sun and Han 2020b) and lactation rooms (Wang et al. 2020b).

A national survey in the USA showed that on average, people spent over $80 \%$ of their time in various types of indoor spaces (Klepeis et al. 2001). Recent surveys indicated a consistent rise of sedentary lifestyles in the general population (ACC 2019; Gong et al. 2019). It is thus of particular importance to understand the dispersion, transport and deposition of respiratory droplets and associated aerosol particles in these environments for infection prevention and control. In this domain, studies have shown that the trajectories of respiratory droplets were dominated by droplet size and ambient airflows (Feng et al. 2020; Mittal et al. 2020; Wei and Li 2016). Specifically, when an individual coughs or talks, droplets are expelled from the source with a wide range of size distribution from 0.1 to $1000 \mu \mathrm{m}$ (Chao et al. 2009; Wells 1934; Yang et al. 2007). Due to gravitational settling, large droplets (e.g., > $100 \mu \mathrm{m})$ would rapidly settle on the floor in a few seconds (Wei and Li 2015). Small droplets and microdroplets $(<30 \mu \mathrm{m})$, which represent the majority of droplets generated by human coughs, speeches and breaths (Chao et al. 2009; Duguid 1946; Yang et al. 2007; Rapineni and Rosenthal 1997), would remain suspended in the atmosphere while being quickly evaporated into droplet nuclei (Morawska 2006), where their motions are dominated by airflows rather than gravity or inertia (Morawska et al. 2020; Zhu et al. 2006).

Further, recent studies indicated that high concentrations of aerosol particles could significantly increase the susceptibility of COVID-19 infection and symptom aggravation in infected individuals (Accarino et al. 2020; Fattorini et al. 2020; Roviello et al. 2020; Travaglio et al. 2020). A known contributing factor is that airborne particles are capable of harboring pathogens by forming clusters with droplets and droplet nuclei and facilitate their long-distance transport (Alonso et al. 2014; Zhao et al. 2019). Recent findings on virus-laden atmospheric fine particulates in Northern Italy, an area burdened with air pollution, supported this hypothesis (Paital et al. 2020; Setti et al. 2020a, 2020b). In indoor environments, various types of human activities (e.g., smoking, cooking, laser printing and incense burning) can emit abundant quantities of aerosol particles, which can stay airborne for long periods of time while acting as potential carriers for airborne pathogens (Mahabee-Gittens et al. 2020; Qu et al. 2020; Tang et al. 2020). Overall, considering people spend most of their time in various indoor spaces, it is of importance to investigate and evaluate the factors for the dispersion and transport of small droplets, droplet nuclei and other emitted aerosol particles.

\section{Human thermal plume: Formation, characteristics and influencing factors}

As part of the thermoregulation process, the human body is constantly exchanging metabolic heat with the surrounding air (Craven and Settles 2006). For thermal comfort, indoor temperature is generally recommended to be within 20-27 ${ }^{\circ} \mathrm{C}$ (CDC 2015), which is approximately $7-13{ }^{\circ} \mathrm{C}$ lower than the normal skin temperature of human body (Licina et al. 2014). The persistence of a body-to-air temperature gradient creates constant heat exchange and directional airflows, often referred to as human thermal plume, that are going upwards due to the thermal buoyancy effect (Fig. 2). In a typical indoor environment with a calm atmosphere, thermal plume plays an essential role in transporting
Fig. 2 Schlieren image of simulated human thermal plume in front view, captured using a single-mirror coincident schlieren system. (a) A thermal manikin with a similar skin temperature to human was used to simulate the heat release from human body in the upright sitting posture. (b) A verticalknife-edge schlieren image of the thermal plume generated on the thermal manikin. Reprinted with permission of Springer from Gena et al. (Gena et al. 2020)
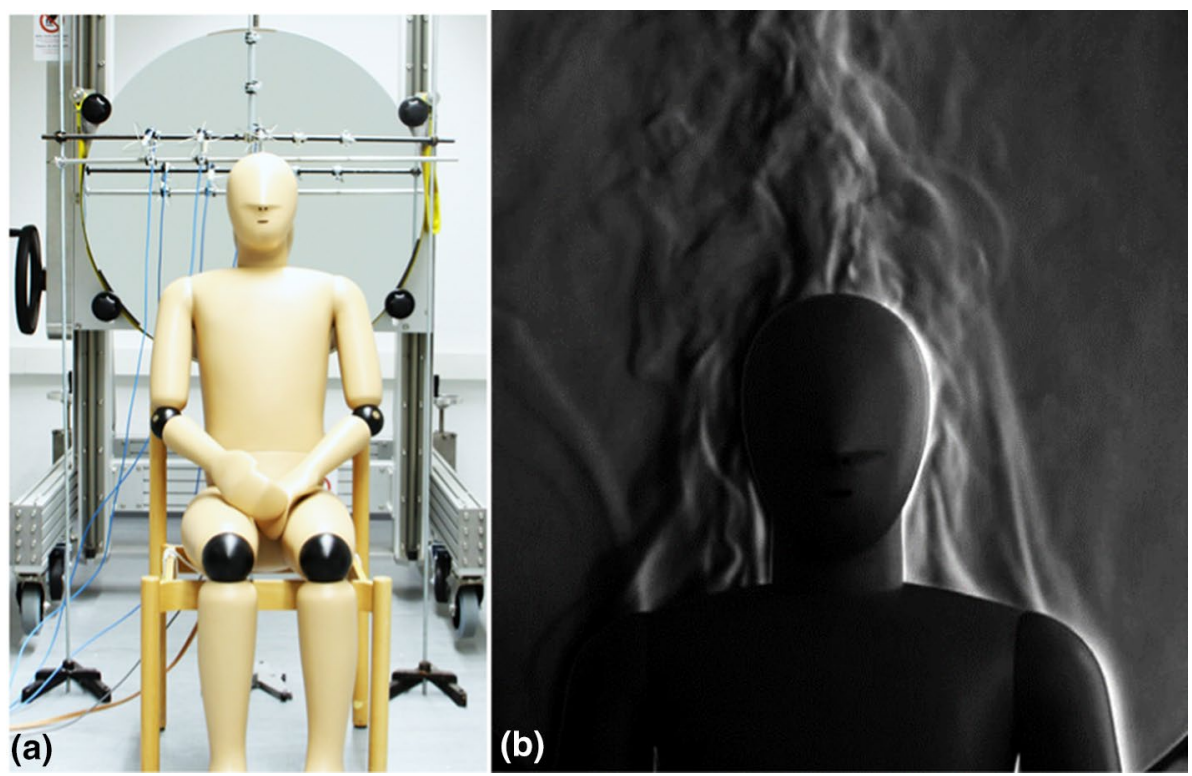
aerosols in the human microenvironment. For an adult person in a standing position, the thermal plume starts as a laminar flow from the lower part of the body and rises along the body boundary layer. The uprising laminar flow gradually increases in thickness and velocity and finally converts to a turbulent flow. As an indicative range, the thickness of the thermal plume generally increases from 2 to $4 \mathrm{~mm}$ at a person's knee and thigh to approximately $20 \mathrm{~cm}$ at chest level (Koelblen et al. 2015) and then reaches a maximum velocity of $0.2-0.3 \mathrm{~m} / \mathrm{s}$ about $50 \mathrm{~cm}$ above the person's head (Wei and Li 2016). To put it into perspective, the maximum mean air velocity is approximately $0.1-0.2 \mathrm{~m} / \mathrm{s}$ for spaces in various types of building with mixed ventilation (i.e., $40 \%$ turbulence intensity), according to the current design criteria by the International Organization for Standardization (ISO 2005).

There are various human and environmental factors influencing the intensity and geometry of human thermal plume, including the air temperature, body posture and type of clothing (Koelblen et al. 2015). Previous studies showed that higher temperature gradients between the human body and ambient air could significantly increase the intensity of thermal plume generated (Feng et al. 2020; Voelker et al. 2014). For instance, when the ambient air temperature decreased from 26 to $20^{\circ} \mathrm{C}$ (still in the comfort range), the peak velocity of thermal plume around a seated adult increased by about $50 \%$ (i.e., from 0.16 to $0.24 \mathrm{~m} / \mathrm{s}$ ) (Licina et al. 2014). The human body posture also has a significant impact on the thermal plume generated around a person in a given environment. For indoor occupants with a sedentary lifestyle, local heat convection will be enhanced by extra air streams from legs and thighs, resulting in a much wider and more intense thermal plume around the body (Licina et al. 2014). On the other hand, the velocities of thermal plume generated by lying occupants were found to be lower than those of a standing or sitting position due to a shortage of convection accumulation (Feng et al. 2020). Licina et al. (2014) assessed the impact of clothing on thermal plume formation using a thermal manikin dressed with different types of clothing. The study found that loose clothing could considerably reduce the intensity of thermal plume because of the thermal insulation effect. Specifically, loose clothing caused a $40 \%$ reduction in the maximum velocity of the thermal plume in the manikin's breathing zone compared with the bare skin scenario, due to physical barriers created by folds and collar in addition to the thermal insulation effect. Also, wearing a wig on the bald manikin reduced about $10 \%$ of the maximum velocity of the thermal plume in the facial region. Overall, existing evidence shows that thermal plume is capable of influencing the dispersion and transport of indoor aerosols in the human boundary layer. The characteristics of human thermal plume depend on various factors including ambient temperature, human posture and type of clothing worn on the concerned individual in a given environment (Table 1).

\section{Influences of human thermal plumes on transmission of airborne pathogens in the human microenvironment: Evidence and knowledge gaps}

Being a constant source of directional airflows and thermal buoyancy, human thermal plume has a significant impact in the diffusion and transport of volatile compounds, aerosols and other airborne matter in the human microenvironment. Vianello et al. (2019) utilized a breathing thermal manikin with respiratory patterns and metabolic heat similar to those of adult males to assess the influences of thermal plume on the human inhalation of indoor microplastics. The study found that thermal plume continuously transported microplastics from lower regions of the room into the breathing zone of the sedentary manikin. In an earlier study, Craven and Settles (2006) also pointed out that thermal plume played a major role in transporting exfoliated human skin scales ranging from submicrometer sizes to $50 \mu \mathrm{m}$ to the human breathing zone and further into the indoor air. Under the constant uprising airflows, the vertical transport and human inhalation of indoor aerosols would be particularly enhanced when the emission source is located at lower horizons in proximity to the human occupant (Rim et al. 2009). Salmanzadeh et al. (2012) demonstrated that flows released by an inlet register set on the floor were pulled strongly by the thermal plume toward the human occupant up to the breathing zone and then rising above the person's head (Fig. 3). Similar results were reported by Ansaripour et al. (2016) where researchers simulated human exposure to fine particles emitted from a desktop-level laser printer in a room with displacement ventilation operating at an inlet velocity of $0.2 \mathrm{~m} / \mathrm{s}$. The study found that compared with the unheated one, the heated manikin $\left(32{ }^{\circ} \mathrm{C}\right)$ was exposed to substantially larger quantities of printer emission particles within 25-130 s after the printing started, both in the breathing zone and around the entire upper body of the seated manikin (Fig. 4). To summarize, there is ample evidence indicating that thermal plume creates constant uprising airflows around the human body and therefore has the ability to transport 


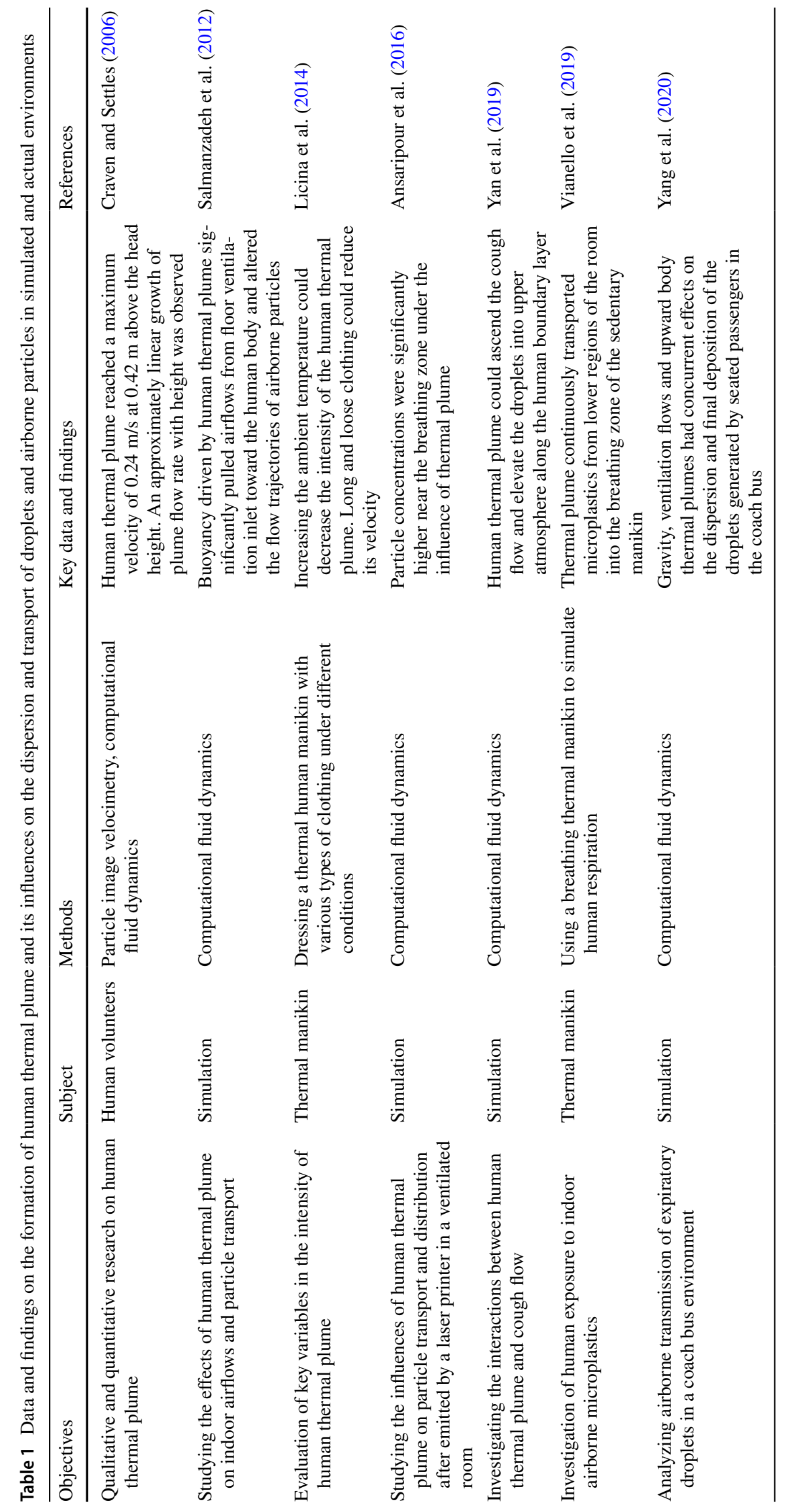




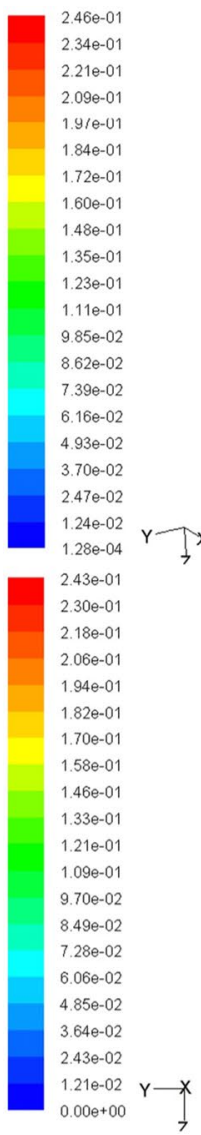

(a)
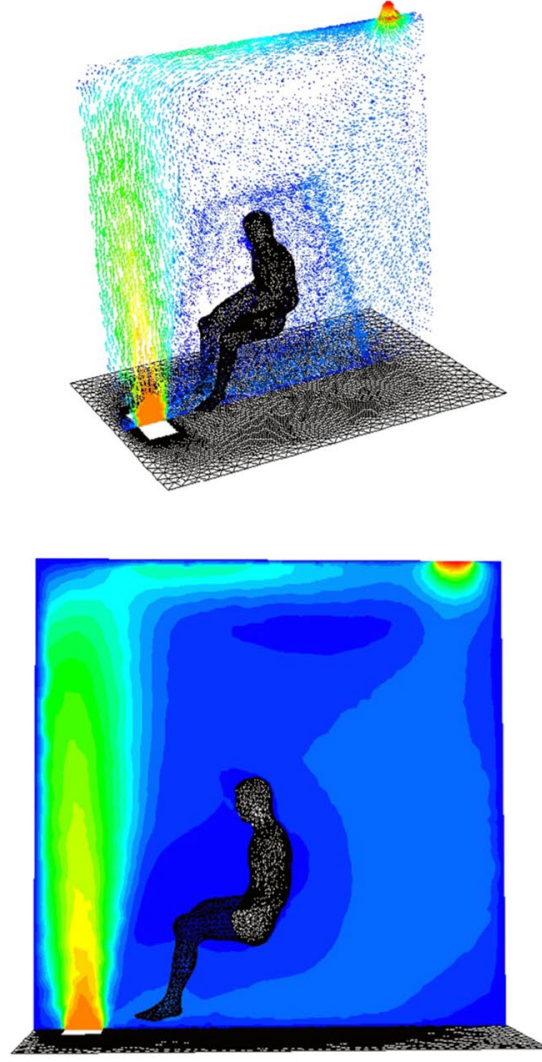

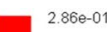

$2.72 \mathrm{e}-01$

$2.57 e-01$

$2.43 \mathrm{e}-01$

$2.29 \mathrm{e}-01$
$2.14 \mathrm{e}-01$

2. $14 \mathrm{e}-0$

$2.00 \mathrm{e}-01$
$1.86 \mathrm{e}-01$

$1.72 \mathrm{e}-01$

$1.57 \mathrm{e}-01$

$1.57 \theta-01$

$1.43 \mathrm{e}-01$

$29 \mathrm{e}-01$

$1.14 \mathrm{e}-01$
$1.00 \mathrm{e}-01$

$8.58 \mathrm{e}-02$

$7.15 \mathrm{e}-02$

$7.15 \mathrm{e}-02$
$5.72 \mathrm{e}-02$

$5.72 \mathrm{e}-02$

$4.30 \mathrm{e}-02$
$2.87 \mathrm{e}-02$

$1.44 \mathrm{e}-02$

$9.94 \mathrm{e}-05$

\section{$7_{2} x$}

(b)

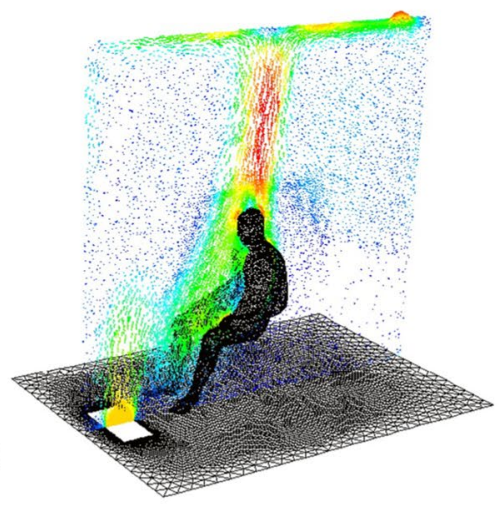

$2.71 \mathrm{e}-01$

$2.57 \mathrm{e}-01$
$2.44 \mathrm{e}-01$

2.44e-01

$2.30 \mathrm{e}-0$

2.17e-0

$2.03 \mathrm{e}-01$
$1.90 \mathrm{e}-01$

$1.76 \mathrm{e}-01$

$1.63 \mathrm{e}-01$

$1.49 \mathrm{e}-01$

$1.35 \mathrm{e}-01$

$1.22 \mathrm{e}-01$

$1.08 \mathrm{e}-01$

9.48e-02

$8.13 \mathrm{e}-02$

$8.13 \mathrm{e}-02$
$6.77 \mathrm{e}-02$

$6.77 \mathrm{e}-02$

$5.42 \mathrm{e}-02$
$4.06 \mathrm{e}-02$

$2.710-02$

$1.35 \mathrm{e}-02$
$0.00 \mathrm{e}+00$

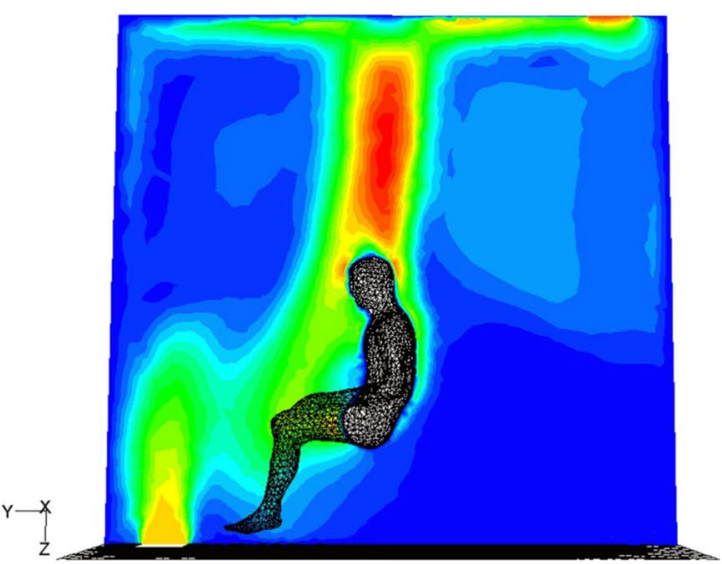

Fig. 3 Comparison on the trajectories of airflows generated by an inlet register installed on the floor in a cubicle $(1.8 \mathrm{~m} \times 2.4 \mathrm{~m} \times 2.4 \mathrm{~m}$, inlet velocity at $0.2 \mathrm{~m} / \mathrm{s}$ ). (a) Unheated manikin showed no disturbance on flow trajectory. (b) Thermal plume generated by the heated manikin $\left(32.2{ }^{\circ} \mathrm{C}\right)$ pulled the flow toward its body, dramatically alter-

abundant quantities of airborne droplets and particles from lower regions to the human breathing zone.

Although there has been no systematic study in the context of COVID-19, studies have shown that human thermal plume can be an important confounding factor in the transmission of airborne pathogens, given the fact that in a calm indoor atmosphere, most inhaled air comes from the body's boundary layer where thermal plume flows through constantly and transports aerosols and other airborne particles to and from (Clark and Cox 1973; Craven and Settles 2006; Melikov 2015; Zhu et al. 2005). Yan et al. (2019) investigated the interactions between the thermal plume and human cough flows using computational fluid dynamic ing its trajectory in the cubicle. Compared with the unheated scenario, a significant portion of the flow reached the breathing zone of the heated manikin and passed through its head. Reprinted with permission of Elsevier from Salmanzadeh et al. (Salmanzadeh et al. 2012)

methods. At the beginning, the cough flow maintained its initial shape and trajectory due to its high jet velocity exiting the source (Fig. 5a). In a few seconds, the flow became substantially weaker and was subsequently ascended by the thermal plume on the sedentary individual. A significant portion of the cough flow was elevated to the upper horizons and accumulated in the air under the influence of thermal plume, which would otherwise remain at lower positions or quickly settle on the floor (Fig. 5b).

There are still questions regarding the influences of different ventilation systems on the human thermal plume in building environments ( $\mathrm{Ge}$ et al. 2013; Yang et al. 2015). Unidirectional airflows induced by mechanical or 

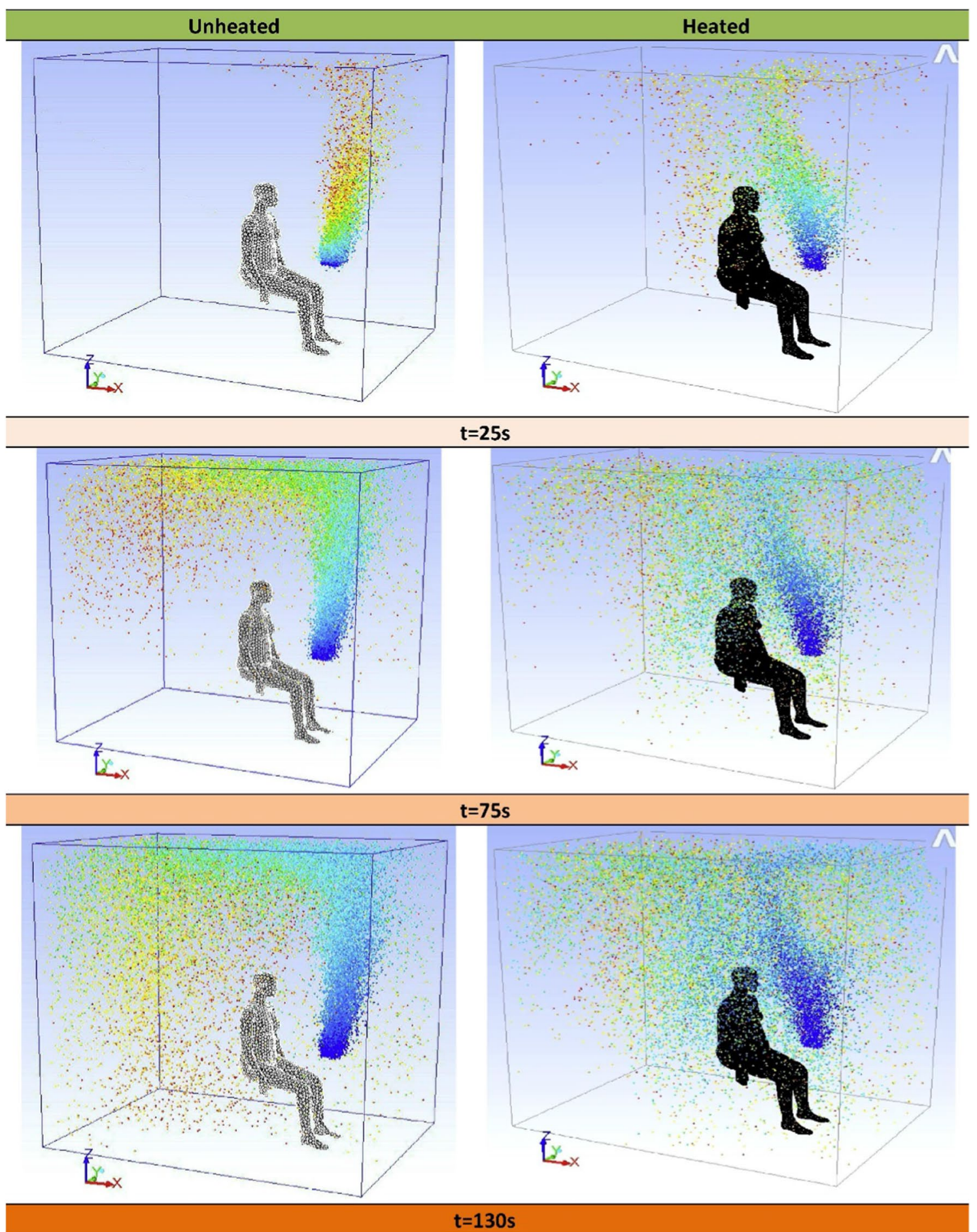

Fig. 4 Dynamic distribution of particles emitted by a desktop-level laser printer in a cubicle with a displacement ventilation system operating at an inlet velocity of $0.2 \mathrm{~m} / \mathrm{s}$. Images above show particle distributions in ambient air at different time intervals around the unheated and heated manikin $\left(32.2{ }^{\circ} \mathrm{C}\right)$. Heating significantly enhanced the transport and accumulation of printer emission particles in the breathing region and around the upper body of the manikin. Reprinted with permission of Elsevier from Ansaripour et al. (Ansaripour et al. 2016) 


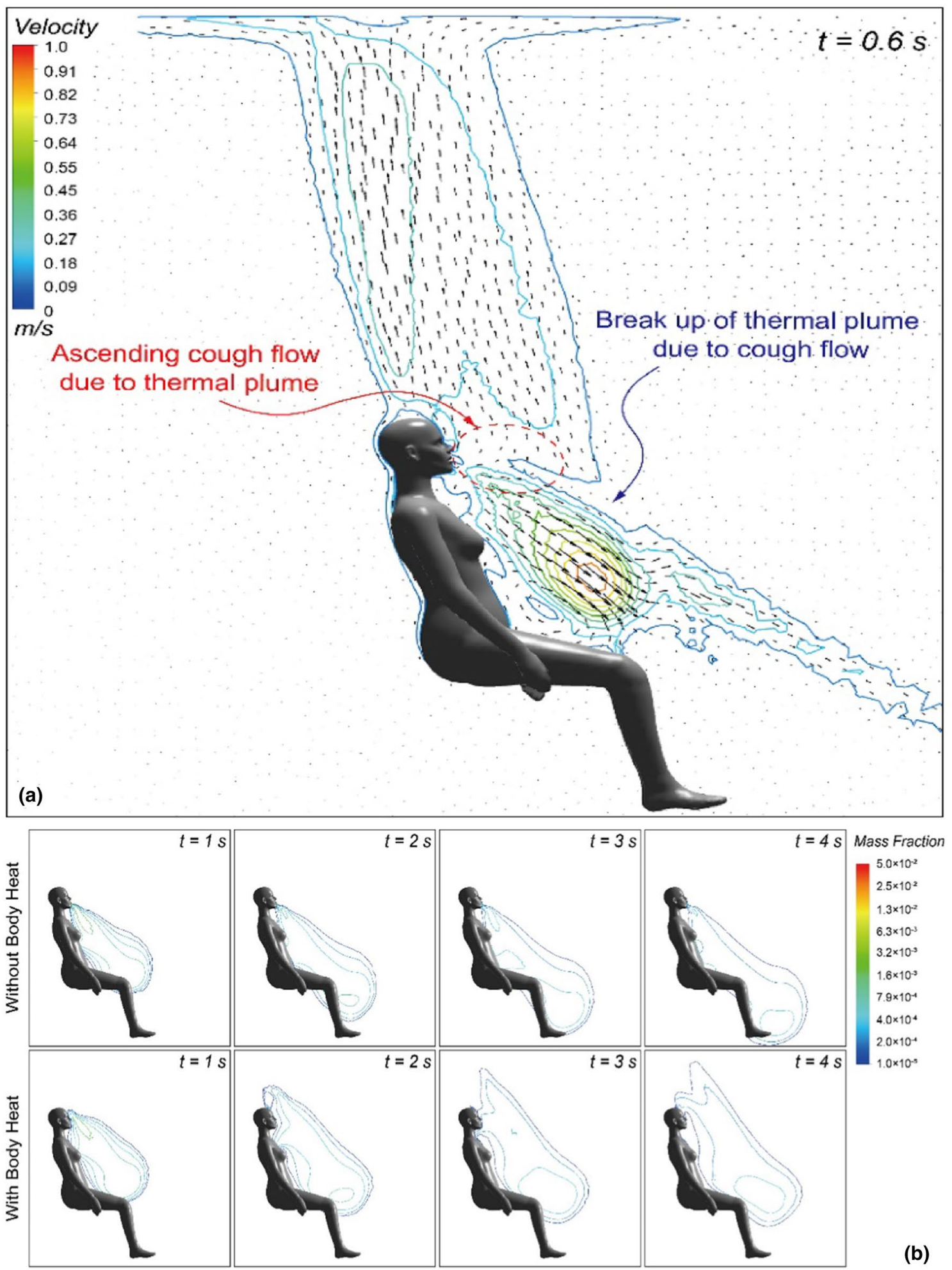

Fig. 5 Impact of human thermal plume on the moving trajectory of a cough flow. (a) Cough flow mixed into the existing human thermal plume at a high jet velocity $(22 \mathrm{~m} / \mathrm{s})$. The latter would ascend droplets into the upper regions, after the cough flow became weakened at $0.6 \mathrm{~s}$ following its expulsion from the mouth. (b) Comparison on the spatial distribution of droplets with unheated and heated manikin after coughing. Without body heat, cough flow maintained its trajec- tory and descended within 1-4 s. Heating of the manikin caused a temperature difference of $5.8^{\circ} \mathrm{C}$ between its surface and ambient air $\left(25^{\circ} \mathrm{C}\right)$. Cough flow was ascended by human thermal plume in the latter scenario where all droplets maintained buoyancy with a significant portion elevated to levels near or above the breathing zone of the sedentary manikin. Reprinted with permission of Elsevier from Yan et al. (Yan et al. 2019) 
natural ventilation, such as opening window or using air conditioning, may affect the thermal plume flow direction and geometry. For instance, displacement ventilation and underfloor air distribution often drive the indoor air to move from the floor to the outlet, which can reduce the accumulation and thickness of the thermal plume, while at the same time increase its velocity. For sedentary occupants in enclosed spaces, thermal plume often has a significant and persistent influence on the transport of respiratory droplets and airborne particles, despite the coexisting influences of ventilation. This was demonstrated in a recent study where researchers simulated the transport of expiratory droplets with initial sizes of 10 and $50 \mu \mathrm{m}$ in a coach bus environment (Yang et al. 2020). The study showed that gravity, ventilation flows and upward body thermal plumes had concurrent effects on the dispersion and final deposition of the droplets generated by seated passengers in the enclosed environment. Similar findings were reported in other studies where thermal plume showed significant influences on the transport of airflows and airborne particles in various indoor environments with mechanical ventilation in operation (Ansaripour et al. 2016; Bivolarova et al. 2017; Salmanzadeh et al. 2012).

Regarding airborne transmission of COVID-19, current studies and risk mitigation efforts have emphasized on the influences of macroenvironments, such as maintaining adequate social distancing and natural ventilation in public spaces, to reduce the spread of SARS-CoV-2 through air (Amoatey et al. 2020; Fang et al. 2020; Lu et al. 2020; US EPA 2020b). Contrastingly, few studies examined how the inhalation process actually proceeds in the human microenvironment (e.g., airflows and aerosols moving toward and through the human breathing zone) and what dominant factors are present therein. Specifically, the significant influences of human thermal plume on the aerosol transport dynamics in the human boundary layer have been barely mentioned in recent studies and scholarly discussions revolving COVID-19. Meanwhile, persisting situations from the current pandemic are posing unprecedented challenges for infection prevention and control, particularly with respect to the airborne transmission route, in enclosed public spaces with high occupancy or foot traffic. In light of this knowledge gap, it is imperative to scrutinize the human microenvironment, including the role of thermal plume in effectuating the transmission of SARS-CoV-2 in various indoor environments, to add to the current understanding of airborne transmission through virus-laden droplets and particles.

Before we attain a solid understanding on this matter, several precautionary measures may be worth considering to mitigate the risks of inhaling virus-laden droplets and particles rising from the floors and lower regions of the indoor atmosphere under the constant uprising airflows induced by human thermal plume. Where practical, removing carpeting and keeping floors clean and disinfected, eliminating sources of indoor aerosol emissions (e.g., tobacco smoking, laser printing), maintaining adequate natural ventilation to reduce aerosol accumulation (Gennaro et al. 2014) and using air purification methods (Fahri et al. 2020; Gopinath et al. 2018) would all be effective methods to mitigate such risks. For sedentary individuals, moving their body closer to desk can partly block the uprising thermal plume and reduce its velocity entering the breathing zone (Melikov 2015; Licina et al. 2014). Lastly, wearing long and loose clothing also reduces the magnitude of thermal plume generated on the person in a given environment, compared with wearing tight clothing or exposing bare skins. To conclude, existing evidence suggests that human thermal plume may play an important role in the airborne transmission of COVID-19 and other pathogens in calm indoor environments, despite the current knowledge gaps. Meanwhile, precautionary measures could be taken to mitigate the underlying risks, such as reducing indoor particle emissions, increasing natural ventilation and dressing long and loose clothing to reduce the intensity and effects of human thermal plume.

\section{Conclusion}

A question raised in earlier debates, airborne transmission via small droplets and particles, has been recently acknowledged as an important route of virus spread in the COVID-19 pandemic. Revolving this matter, recent studies, scholarly discussions and regulatory guidelines have mostly emphasized on the macro aspects (e.g.,., social distancing, restrictions on using air circulation in public spaces), while there are few studies or discussions on the human microenvironment which constitutes the critical last step for airborne transmission to effectuate. Generated by body-to-air temperature gradients, human thermal plume creates persistent uprising airflows along the human boundary layer, typically as a laminar-to-turbulent flow with varying thicknesses from $2-4 \mathrm{~mm}$ to $200 \mathrm{~mm}$ and a maximum velocity of $0.2-0.3 \mathrm{~m} / \mathrm{s}$, which is comparable to the designed air velocity in various buildings with mixed ventilation under the current design criteria. Being a constant source of directional airflows and thermal buoyancy, in a clam indoor environment thermal plume plays a significant or even dominant role in the aerosol transport dynamics in the human boundary layer where most inhaled air comes from. Existing evidence shows that thermal plume has significant influences on the diffusion and transport of volatile compounds, exfoliated human skin scales and airborne microplastics into the human breathing zone in typical indoor environments. Meanwhile, 
thermal plume promotes the dispersion of human respiratory droplets from the source by ascending them along the boundary layer and into the upper atmosphere. Based on the mechanisms and key variables in the formation of thermal plume (e.g., ambient temperature, body posture and type of clothing), several precautionary measures may be put in the place to reduce the risks associated with thermal plume and its induced aerosol transport in the human microenvironment. Where possible, eliminating the sources of indoor particle emissions (e.g., smoking, cooking, laser printing), maintaining natural ventilation, moving body closer to desk and wearing long and loose clothing can reduce the magnitude or influences of thermal plume and the resultant risks of inhaling virus-laden droplets and particles rising from lower regions in indoor spaces. Given that people spent most of their time in various indoor environments and there is an increasing trend of adopting sedentary lifestyles in the global population, it is of significance to further study the roles of thermal plume and the human microenvironments in the airborne transmission of COVID-19 and other human respiratory pathogens, especially in enclosed public spaces.

Acknowledgement This work was funded by the Young Talent Support Plan of Xi'an Jiaotong University.

\section{Compliance with ethical standards}

Conflict of interest The authors declare that they have no conflict of interest in this work.

\section{References}

Accarino G, Lorenzetti S, Aloisio G (2020) Assessing correlations between short-term exposure to atmospheric pollutants and COVID-19 spread in all Italian territorial areas. Environ Pollut 268:115714. https://doi.org/10.1016/j.envpol.2020.115714

Alonso C, Goede DP, Morrison RB et al (2014) Evidence of infectivity of airborne porcine epidemic diarrhea virus and detection of airborne viral RNA at long distances from infected herds. Vet Res 45(1):73. https://doi.org/10.1186/s13567-014-0073-z

ACC (2019) American College of Cardiology. Trends in US Sedentary Behavior, 2001-2016. https://www.acc.org/latest-in-cardiology /journal-scans/2019/04/24/13/23/trends-in-sedentary-behavioramong-the-us. (accessed 19 December 2020)

Amoatey P, Omidvarborna H, Baawain MS, Al-Mamun A (2020) Impact of building ventilation systems and habitual indoor incense burning on SARS-CoV-2 virus transmissions in Middle Eastern countries. Sci Total Environ 733:139356. https://doi. org/10.1016/j.scitotenv.2020.139356

Ansaripour M, Abdolzadeh M, Sargazizadeh S (2016) Computational modeling of particle transport and distribution emitted from a Laser jet printer in a ventilated room with different ventilation configurations. Appl Therm Eng 103(25):920-933. https://doi. org/10.1016/j.applthermaleng.2016.04.137

Bivolarova M, Kierat W, Zavrl E et al (2017) Effect of airflow interaction in the breathing zone on exposure to bioeffluents.
Build Environ 125:216-226. https://doi.org/10.1016/j.build env.2017.08.043

CDC (2020a) Centers for Disease Control and Prevention. How COVID-19 Spreads. https://www.cdc.gov/coronavirus/2019ncov/prevent-getting-sick/how-covid-spreads.html. (accessed 19 December 2020)

CDC (2020b) Centers for Disease Control and Prevention. Interim guidance on management of coronavirus disease 2019 (COVID19) in correctional and detention facilities. www.cdc.gov/coron avirus/2019-ncov/community/correction-detention/guidancecorrectional-detention.html. (accessed 19 December 2020)

CDC (2015) Centers for Disease Control and Prevention. Indoor environmental quality. https://www.cdc.gov/niosh/topics/indoorenv/ temperature.html\#: :text=Assuming. (accessed 19 December 2020)

Chao CYH, Wan MP, Morawska L et al (2009) Characterization of expiration air jets and droplet size distributions immediately at the mouth opening. Aerosol Sci 40:122-133. https://doi. org/10.1016/j.jaerosci.2008.10.003

Clark RP, Cox RN (1973) "The generation of aerosols from the human body", in Airborne Transmission and Airborne Infection: Concepts and Methods. Wiley, New York, Chap 95:413-426

Craven B, Settles G (2006) A computational and experimental investigation of the human thermal plume. J Fluids Eng 128(6):12511258. https://doi.org/10.1115/1.2353274

de Gennaro G, Dambruoso PR, Loiotile AD et al (2014) Indoor air quality in schools. Environ Chem Lett 12:467-482. https://doi. org/10.1007/s10311-014-0470-6

Duguid JP (1946) The size and the duration of air-carriage of respiratory droplets and droplet-nuclei. J Hyg 44(6):471-479. https:// doi.org/10.1017/S0022172400019288

Fahri F, Bacha K, Chiki FF et al (2020) Air pollution: new bio-based ionic liquids absorb both hydrophobic and hydrophilic volatile organic compounds with high efficiency. Environ Chem Lett 18:1403-1411. https://doi.org/10.1007/s10311-020-01007-8

Fang D, Pan S, Li Z et al (2020) Large-scale public venues as medical emergency sites in disasters: lessons from COVID-19 and the use of Fangcang shelter hospitals in Wuhan. BMJ Glob Health, China. https://doi.org/10.1136/bmjgh-2020-002815

Fattorini D, Francesco R (2020) Role of the chronic air pollution levels in the Covid-19 outbreak risk in Italy. Environ Res 264:114732. https://doi.org/10.1016/j.envpol.2020.114732

Fears AC, Klimstra WB, Duprex P et al (2020) Persistence of Severe Acute Respiratory Syndrome Coronavirus 2 in Aerosol Suspensions. Emerg Infect Dis. https://doi.org/10.3201/eid2609.201806

Feng G, Bi Y, Zhang Y et al (2020) Study on the motion law of aerosols produced by human respiration under the action of thermal plume of different intensities. Sustain Cities Soc 54:101935. https://doi. org/10.1016/j.scs.2019.101935

Gena AW, Voelker C, Settles GS (2020) Qualitative and quantitative schlieren optical measurement of the human thermal plume. Indoor Air 30(4):757-766. https://doi.org/10.1111/ina.12674

Ge Q, Li X, Inthavong K, Tu J (2013) Numerical study of the effects of human body heat on particle transport and inhalation in indoor environment. Build Environ 59:1-9. https://doi.org/10.1016/j. buildenv.2012.08.002

Gong W, Fong DY, Wang M et al (2019) Increasing socioeconomic disparities in sedentary behaviors in Chinese children. BMC Public Health 19:754. https://doi.org/10.1186/s12889-019-7092-7

Gopinath A, Kadirvelu K (2018) Strategies to design modified activated carbon fibers for the decontamination of water and air. Environ Chem Lett 16:1137-1168. https://doi.org/10.1007/s1031 1-018-0740-9

Han J, Zhang X, He S et al (2020) Can the coronavirus disease be transmitted from food? A review of evidence, risks, policies and 
knowledge gaps. Environ Chem Lett. https://doi.org/10.1007/ s10311-020-01101-x

ISO (2005) International Organization for Standardization. Ergonomics of the thermal environment - Analytical determination and interpretation of thermal comfort using calculation of the PMV and PPD indices and local thermal comfort criteria (ISO 7730:2005).

Klepeis NE, Nelson WC, Ott WR et al (2001) The National Human Activity Pattern Survey (NHAPS): a resource for assessing exposure to environmental pollution. J Expo Anal Environ Epidemiol 11(3):231-252. https://doi.org/10.1038/sj.jea.7500165

Koelblen B, Bogdan A (2015) Impact of clothing, breathing and body posture on the shaping of a thermal plume above a human. Int J Vent 13(4):397-410. https://doi.org/10.1080/14733 315.2015 .11684063

Lewis D (2020) Mounting evidence suggests coronavirus is airborne - but health advice has not caught up. Nature. https://media.natur e.com/original/magazine-assets/d41586-020-02058-1/d4158 6-020-02058-1.pdf. (accessed 19 December 2020)

Licina D, Pantelic J, Melikov AK et al (2014) Experimental investigation of the human convective boundary layer in a quiescent indoor environment. Build Environ 75:79-91. https://doi.org/10.1016/j. buildenv.2014.01.016

Lu J, Gu J, Li K et al (2020) COVID-19 outbreak associated with air conditioning in restaurant, 60 Guangzhou, China, 2020. Emerging Infect Dis. https://doi.org/10.3201/eid2607.200764

Mahabee-Gittens EM, Merianos AL, Mat GE (2020) Letter to the Editor Regarding: "An imperative need for research on the role of environmental factors in transmission of novel coronavirus (COVID-19)" secondhand and thirdhand smoke as potential sources of COVID-19. Environ Sci Technol 54(9):5309-5310. https://doi.org/10.1021/acs.est.0c02041

Melikov AK (2015) Human body micro-environment: The benefits of controlling airflow interaction. Build Environ 91:70-77. https ://doi.org/10.1016/j.buildenv.2015.04.010

Mittal R, Ni R, Seo JH (2020) The flow physics of COVID-19. J Fluid Mech. https://doi.org/10.1017/jfm.2020.330

Morawska L (2006) Droplet fate in indoor environments, or can we prevent the spread of infection? Indoor Air 16:335-347. https ://doi.org/10.1111/j.1600-0668.2006.00432.x

Morawska L, Miltion DK (2020) It is time to address airborne transmission of COVID-19. Clin Infect Dis. https://doi.org/10.1093/ $\mathrm{cid} / \mathrm{ciaa} 939$

Paital B, Agrawal PK (2020) Air pollution by $\mathrm{NO}_{2}$ and $\mathrm{PM}_{2.5}$ explains COVID-19 infection severity by overexpression of angiotensin-converting enzyme 2 in respiratory cells: a review. Environ Chem Lett. https://doi.org/https://doi.org/10.1007/ s10311-020-01091-w

Qu G, Li X, Hu L, Jiang G (2020) An Imperative Need for Research on the Role of Environmental Factors in Transmission of Novel Coronavirus (COVID-19). Environ Sci Technol 54:3730-3732. https://doi.org/10.1021/acs.est.0c01102

Rapineni RS, Rosenthal FS (1997) The size distribution of droplets in the exhaled breath of healthy human subjects. J Aerosol Med 10(2):105-106. https://doi.org/10.1089/jam.1997.10.105

Rim D, Novoselac A (2009) Transport of particulate and gaseous pollutants in the vicinity of a human body. Build Environ 44:1840-1849. https://doi.org/10.1016/j.buildenv.2008.12.009

Roviello V, Roviello GN (2020) Lower COVID-19 mortality in Italian forested areas suggests immunoprotection by Mediterranean plants. Environ Chem Lett. https://doi.org/10.1007/s10311-020-01063-0

Salmanzadeh M, Zahedi G, Ahmadi G et al (2012) Computational modeling of effects of thermal plume adjacent to the body on the indoor airflow and particle transport. J Aerosol Sci 53:2939. https://doi.org/10.1016/j.jaerosci.2012.05.005

Setti L, Passarini F, Gennaro GD et al (2020) Airborne Transmission Route of COVID-19: Why 2 meters/6 feet of inter-personal distance could not be enough. Int J Environ Res Public Health 17(8):2932. https://doi.org/10.3390/ijerph17082932

Setti L, Passarini F, Gennaro GD et al (2020) SARS-Cov-2 RNA found on particulate matter of Bergamo in Northern Italy: First evidence. Environ Res 188:109754-109754. https://doi. org/10.1016/j.envres.2020.109754

Sun S, Han J (2020) Open defecation and squat toilets, an overlooked risk of fecal transmission of COVID-19 and other pathogens in developing communities. Environ Chem Lett. https://doi. org/10.1007/s10311-020-01143-1

Sun S, Han J (2020) Unflushable or missing toilet paper, the dilemma for developing communities during the COVID-19 episode. Environ Chem Lett. https://doi.org/10.1007/s10311-020-01064-Z

Tang S, Mao Y, Jones RM et al (2020) Aerosol transmission of SARS-CoV-2? Evidence, prevention and control. Environ Int 144:106039. https://doi.org/10.1016/j.envint.2020.106039

Travaglio M, Yu Y, Popovic R, Selley, et al (2020) Links between air pollution and COVID-19 in England. Environ Pollut 268:115859. https://doi.org/10.1016/j.envpol.2020.115859

US EPA (2020a) United States Environmental Protection Agency. Indoor Air and Coronavirus (COVID-19). https://www.epa. gov/coronavirus/indoor-air-and-coronavirus-covid-19 (accessed 17December 2020)

US EPA (2020b) United State Environmental Protection Agency. Ventilation and Coronavirus (COVID-19). https://www.epa.gov/ coronavirus/ventilation-and-coronavirus-covid-19. (accessed 19 December 2020)

van Doremalen N, Bushmaker T, Morris DH et al (2020) Aerosol and surface stability of SARS- CoV-2 as compared with SARS-CoV-1. N Engl J Med 382(16):1564-1567. https://doi.org/10.1056/ NEJMc2004973

Vianello A, Jensen RL, Liu L et al (2019) Simulating human exposure to indoor airborne microplastics using a breathing thermal manikin. Sci Rep 9:8670. https://doi.org/10.1038/s41598-019-45054-w

Voelker C, Maemple S, Kornadt O (2014) Measuring the human body's microclimate using a thermalmanikin. Indoor Air 24:567-579. https://doi.org/10.1111/ina.12112

Wang X, Sun S, Zhang B et al (2020) Solar heating to inactivate thermal-sensitive pathogenic microorganisms in vehicles: application to COVID-19. Environ Chem Lett. https://doi.org/10.1007/s1031 1-020-01132-4

Wang X, Han J, Lichtfouse E (2020b) Unprotected mothers and infants breastfeeding in public amenities during the COVID-19 pandemic. Environ Chem Lett 18:1447-1450. https://doi.org/10.1007/s1031 1-020-01054-1

Wei J, Li Y (2015) Enhanced spread of expiratory droplets by turbulence in a cough jet. Build Environ 93:86-96. https://doi. org/10.1016/j.buildenv.2015.06.018

Wei J, Li Y (2016) Airborne spread of infectious agents in the indoor environment. Am J Infect Control 44:S102-S108. https://doi. org/10.1016/j.ajic.2016.06.003

Wells WF (1934) On air-borne infection-Study II droplets and droplet nuclei. Am J Hyg 20:611-618. https://doi.org/10.1093/oxfordjour nals.aje.a118097

WHO (2020a) World Health Organization. Transmission of SARSCov-2: implications for infection prevention precautions. https ://www.who.int/news-room/commentaries/detail/transmissionof-sars-cov-2-implications-for-infection-prevention-precautions. Accessed 19 Dec 2020

WHO (2020b) World Health Organization. Advice on the masks in the context of COVID-19: interim guidance, 2020. https://apps. who.int/iris/bitstream/handle/10665/332293/WHO-2019-nCovIPC_Masks-2020.4-eng.pdf. Accessed 19 Dec 2020

WHO (2020c) World Health Organization. Modes of transmission of virus causing COVID-19: implications for IPC precaution recommendations. https://www.who.int/news-room/commentaries/detai 
1/modes-of-transmission-of-virus-causing-covid-19-implicatio ns-for-ipc-precaution-recommendations. Accessed 19 Dec 2020

Yan Y, Li X, Tu J (2019) Thermal effect of human body on cough droplets evaporation and dispersion in an enclosed space. Build Environ 148:96-106. https://doi.org/10.1016/j.buildenv.2018.10.039

Yang S, Lee G, Chen C et al (2007) The size and concentration of droplets generated by coughing in human subjects. J Aerosol Med 20(4):484-494. https://doi.org/10.1089/jam.2007.0610

Yang X, Ou C, Yang H et al (2020) Transmission of pathogen-laden expiratory droplets in a coach bus. J Hazard Mater 397:122609. https://doi.org/10.1016/j.jhazmat.2020.122609

Yang C, Yang X, Zhao B (2015) The ventilation needed to control thermal plume and particle dispersion from manikins in a unidirectional ventilated protective isolation room. Build Simul 8:551-565. https://doi.org/10.1007/s12273-014-0227-6
Zhao Y, Richardson B, Takle E et al (2019) Airborne transmission may have played a role in the spread of 2015 highly pathogenic avian influenza outbreaks in the United States. Sci Rep 9(1):11755. https ://doi.org/10.1038/s41598-019-47788-z

Zhu S, Kato S, Murakami S, Hayashi T (2005) Study on inhalation region by means of CFD analysis and experiment. Build Environ 40:1329-1336. https://doi.org/10.1016/j.buildenv.2004.11.009

Zhu S, Kato S, Yang J (2006) Study on transport characteristics of saliva droplets produced by coughing in a calm indoor environment. Build Environ 41(12):1691-1702. https://doi.org/10.1016/j. buildenv.2005.06.024

Publisher's Note Springer Nature remains neutral with regard to jurisdictional claims in published maps and institutional affiliations. 